\title{
Joining of Stainless Steel with Novel Filler Material and its Weldability Studies ${ }^{\dagger}$
}

\author{
Koushik Kosanam ${ }^{1, *}$, Nataraj JR ${ }^{2}$ \\ 1 Manufacturing System Engineering and Management Department, California State University, Northridge; \\ koushikkosanam1897@gmail.com (K.K.); \\ 2 Mechanical department, RV College of Engineering; natarajjr@rvce.edu.in (N.J.R.); \\ * Correspondence: koushikkosanam1897@gmail.com; \\ $\dagger$ Presented at Materials Chemistry and Physics (Materials Chemistry 2020) - International e-Conference
}

Received: 16.09.2020; Revised: 20.09.2020; Accepted: 24.09.2020; Published: 27.09.2020

\begin{abstract}
Welding of Austenitic Stainless steels results in the emission of hexavalent chromium $\left[\mathrm{Cr}^{+6}\right]$ fumes due to the presence of $18-22 \%$ chromium content in the stainless steel base and its filler materials. These hexavalent fumes are carcinogenic and cause respiratory problems to the welders and personnel in the vicinity of welding. In the present research work, novel Chromium free Nickel-based filler material of $\%$ wt composition $41 \mathrm{Ni}, 8 \mathrm{Co}, 16 \mathrm{Fe}, 14 \mathrm{Mo}, 7 \mathrm{Mn}, 8 \mathrm{Cu}, 3 \mathrm{Nb}, 1 \mathrm{Ti}, 1 \mathrm{Si}, 1 \mathrm{Al}$ is developed and its weldability with stainless steel is studied. The microstructure and chemical composition of different metallurgical phases in the filler material and weld joints are studied using different microscopy tools and X-Ray Diffraction, respectively. The ultimate tensile strength of the filler material and weld joint welded by developed filler material is found to be $536 \mathrm{MPa}$ and $487 \mathrm{MPa}$, respectively. The average hardness and toughness of the filler material and welded joint are 190VHN \&110J and 209VHN \& 89 VHN, respectively. Results of Potentio-dynamic polarization and Inter Granular corrosion cracking (IGCC) of the weld joint has shown the corrosion rate of $1.575 \mathrm{e}-004$ mils/year and 354.56 miles/year, respectively. Mechanical properties and corrosion rate of weldments welded by novel filler material are compared with that of conventional filler material. Design of experiments(DOE) using Taguchi L9 array is formulated to understand the influence of Welding current, root gap, and gas flow rate on output parameters such as Tensile Strength, Toughness, and corrosion resistance of weldment. DOE using RSM has shown maximum Tensile strength of 487Mpa, maximum Hardness of $209 \mathrm{VHN}$, and a minimum corrosion rate of $1.575 \mathrm{e}-004$ mils/year has obtained with an optimum current value of 130A, 11.79 litres/min gas flow rate, and $2.33 \mathrm{~mm}$ root gap.
\end{abstract}

Keywords: stainless steel; filler material; welding; hexavalent chromium fumes; potentiodynamic polarization; Taguchi; intergranular stress corrosion cracking

(C) 2020 by the authors. This article is an open-access article distributed under the terms and conditions of the Creative Commons Attribution (CC BY) license (https://creativecommons.org/licenses/by/4.0/).

\section{Funding}

This research received no external funding.

\section{Acknowledgments}

We would like to thank the RV College of Engineering and California State University, Northridge, for their technical and administration support. 


\section{Conflicts of Interest}

The authors declare no conflict of interest." There are no personal circumstances or interest that may be perceived as inappropriately influencing the representation or interpretation of reported research results and this research work had no external funders. 